\title{
Faktor yang Memengaruhi Penurunan Cakupan Imunisasi pada Masa Pandemi Covid-19 di Jakarta
}

\author{
Sreshta Mukhi, Bernie Endyarni Medise \\ Departemen Ilmu Kesehatan Anak Fakultas Kedokteran Universitas Indonesia Rumah Sakit Dr. Cipto Mangunkusumo, Jakarta
}

Latar belakang. Pandemi Covid-19 sangat memengaruhi pelayanan imunisasi di seluruh dunia. Tenaga kesehatan dialihkan untuk pelayanan Covid-19 dan orangtua merasa takut membawa anaknya untuk imunisasi ke fasilitas kesehatan sehingga menurunkan cakupan imunisasi. Penurunan cakupan imunisasi akan meningkatkan kejadian penyakit yang dapat dicegah dengan imunisasi (PD3I). Jakarta sebagai ibukota negara adalah kota dengan populasi terbesar dan juga kasus Covid-19 terbanyak di Indonesia.

Tujuan. Mengetahui faktor-faktor yang memengaruhi penurunan cakupan imunisasi di Jakarta dari sudut pandang orangtua dan tenaga kesehatan.

Metode. Penelitian potong lintang menggunakan kuesioner disebarkan kepada tenaga kesehatan (dokter spesialis anak, dokter umum, perawat, bidan, kader) dan orangtua di Jakarta pada bulan Agustus hingga September 2020. Hasil di evaluasi menggunakan SPSS. Hasil. Sebanyak 125 tenaga kesehatan dan 145 orangtua mengikuti penelitian ini. Tenaga kesehatan menghadapi masalah seperti adanya peraturan pemerintah untuk menghentikan sementara pelayanan imunisasi, kurangnya alat pelindung diri (APD), tenaga kesehatan terinfeksi Covid-19 dan tenaga imunisasi dialihkan untuk pelayanan Covid-19. Masalah pada orangtua antara lain keraguan untuk membawa anaknya imunisasi karena takut tertular Covid-19 dari tenaga kesehatan ataupun pasien lain, Posyandu ditutup, adanya peraturan PSBB dan masalah transportasi.

Kesimpulan. Penurunan cakupan imunisasi pada masa pandemi Covid-19 disebabkan oleh multi faktor yang harus diminimalisasi untuk mengurangi kejadian PD3I. Sari Pediatri 2021;22(6):336-42

Kata kunci: imunisasi, pandemi, Covid-19, cakupan imunisasi, penyakit yang dapat dicegah dengan imunisasi

\section{Factors that Affect Decrease in Immunization Coverage in Jakarta during The Covid-19 Pandemic}

Sreshta Mukhi, Bernie Endyarni Medise

Background. Covid-19 pandemic has disrupted immunization programs worldwide. Health workers are busy with Covid-19 services and parents are hesitant to bring their children for immunizations. The decrease in immunization coverage may increase the incidence of vaccine preventable diseases.

Objective. To find factors that decrease immunization coverage in Jakarta from the point of view of parents and health workers.

Methods. A cross sectional study was done from August to September 2020. Questionnaires were distributed to health workers and parents all over the capital city of Jakarta. Results were evaluated using SPSS.

Result. A total of 125 health workers and 145 parents took part in this study. Health workers were faced with problems such as Government rule to temporarily stop services, difficulty in convincing parents, inadequate PPE, getting infected by Covid-19 and immunization workers diverted to Covid-19 services. Parents are hesitant to bring their children for immunizations due to fear of being infected by health workers or other patients, social restrictions, their usual health centers have stopped immunization services, difficulty in making children wear PPE and transportation problems.

Conclusion. The decrease in immunization coverage during the Covid-19 pandemic is caused by multiple factors that need to be solved in order to minimize vaccine-preventable diseases. Sari Pediatri 2021;22(6):336-42

Key words: immunization, pandemic, Covid-19, immunization coverage, vaccine-preventable diseases

Alamat korespondensi: Bernie Endyarni Medise. Departemen Ilmu Kesehatan Anak Fakultas Kedokteran Universitas Indonesia Rumah Sakit Dr. Cipto Mangunkusumo, Jakarta.Email: bernie.medise@yahoo.com 
Sreshta Mukhi dkk: Faktor yang memengaruhi penurunan cakupan imunisasi pada masa pandemi Covid-19 di DKI Jakarta

I munisasi dapat mencegah kematian pada 2-3 juta anak per tahun yang disebabkan oleh penyakit yang dapat dicegah oleh imunisasi (PD3I). ${ }^{1,2}$ Pandemi Covid-19 telah mengganggu pelayanan kesehatan di seluruh dunia, termasuk pelayanan imunisasi. ${ }^{3}$ Sebagian besar fasilitas kesehatan dan tenaga kesehatan dialihkan untuk pelayanan Covid-19 sehingga pelayanan kesehatan yang penting lainnya, seperti imunisasi menjadi terbengkalai. ${ }^{4}$ Badan kesehatan dunia WHO menyatakan bahwa dampak dari penurunan cakupan imunisasi adalah sekitar 80 juta anak dari 68 negara yang dapat berisiko terinfeksi PD3I, seperti difteri, campak, dan polio. ${ }^{5,6}$

United Nations Children's Fund/UNICEF dan Kementerian Kesehatan Republik Indonesia melaporkan bahwa cakupan imunisasi MR berkurang $13 \%$ dari Januari hingga Maret 2020 dibandingkan dengan periode yang sama pada tahun 2019. ${ }^{7,8}$ Data cakupan imunisasi dari Kementerian Kesehatan menunjukkan bahwa cakupan imunisasi dari Januari hingga Agustus 2020 mengalami penurunan dibandingkan dengan tahun 2019. Contohnya, cakupan imunisasi DPT-HBHib pada tahun 2019 yaitu 98,6\% dan pada tahun 2020 hanya 51,0\%. Cakupan MR pada tahun 2019 yaitu $98,7 \%$ dan pada tahun 2020 menjadi $55,7 \%$. Imunisasi IPV mengalami penurunan yang paling signifikan, yaitu dari 97,3\% pada tahun 2019 menjadi $23,2 \%$ pada tahun $2020 .{ }^{9,10}$

Jakarta sebagai ibukota Indonesia adalah kota dengan populasi terbesar dan juga kasus Covid-19 terbanyak di Indonesia. ${ }^{11}$ Setelah pemerintah mengumumkan kasus Covid-19 pertama pada bulan Maret, diperlakukan peraturan Pembatasan Sosial Berskala Besar (PSBB) di Jakarta yang melarang pengumpulan massa. Oleh karena itu, beberapa fasilitas kesehatan termasuk Posyandu, menghentikan pelayanan imunisasi yang mengakibatkan penurunan cakupan imunisasi. ${ }^{12}$ Besarnya populasi dan kasus Covid-19, serta banyaknya layanan Posyandu yang harus dihentikan sementara, maka DKI Jakarta dipilih untuk menjadi lokasi penelitian ini.

Selain Indonesia dan negara berkembang lainnya, negara maju juga mengalami penurunan cakupan imunisasi. Di Inggris, terdapat penurunan cakupan MMR 19,8\% dan penurunan cakupan vaksin heksavalen 6,7\% dari Februari hingga April 2020 dibandingkan dengan periode yang sama pada tahun sebelumnya. ${ }^{13}$ Di Michigan, Amerika Serikat, cakupan imunisasi pada anak di bawah 5 bulan yaitu $67 \%$ pada tahun 2019 dan mengalami penurunan menjadi $49,7 \%$ pada tahun $2020 .{ }^{14}$

\section{Metode}

Penelitian ini adalah penelitian deskriptif yang menggunakan metode potong lintang. Berdasarkan perhitungan besar sampel didapatkan sampel minimal 103 orangtua dan 103 tenaga kesehatan. Penelitian dilakukan saat pandemi Covid-19 dan peraturan PSBB sedang diterapkan di DKI Jakarta, maka pengumpulan data secara tatap muka tidak mungkin dilaksanakan sehingga survei dilakukan secara daring. Kuesioner Google (Google form) disebarkan kepada orangtua di Jakarta Utara, Jakarta Selatan, Jakarta Timur, Jakarta Barat, dan Jakarta Pusat untuk mendapatkan respon secara menyeluruh. Kuesioner Google juga disebarkan kepada tenaga kesehatan (dokter spesialis anak, dokter umum, perawat, bidan, dan kader imunisasi) yang bekerja di rumah sakit, klinik pribadi, Puskesmas, dan juga Posyandu untuk mengevaluasi permasalahan pelayanan imunisasi pada setiap sektor.

Untuk penelitian yang dilakukan kepada orangtua, kriteria inklusi adalah orangtua yang memiliki anak di bawah 5 tahun dan bersedia mengisi kuesioner. Kriteria eksklusi adalah orangtua yang tidak bersedia mengisi kuesioner. Kuesioner orangtua terdiri dari data demografik dan pertanyaan untuk mengevaluasi permasalahan yang dialami orangtua dalam pemberian imunisasi pada masa pandemi Covid-19.

Untuk penelitian tenaga kesehatan, kriteria inklusi adalah tenaga kesehatan yang bersedia mengisi kuesioner. Kuesioner tenaga kesehatan terdiri dari data demografik serta pertanyaan untuk mengevaluasi permasalahan yang dialami dalam pelayanan imunisasi.

Pertanyaan dibuat berdasarkan pedoman imunisasi pada masa pandemi Covid-19 yang dibuat oleh WHO. ${ }^{15-16}$ Data diperoleh dari bulan Agustus hingga September 2020 pada masa pandemi Covid-19, setelah mendapat izin penelitian dari Komite Etik Universitas Indonesia. Data dievaluasi menggunakaan SPSS.

\section{Hasil}

Seratus duapuluh lima tenaga kesehatan mengikuti penelitian ini, terdiri dari 18 spesialis dokter anak, 44 dokter umum, 13 perawat, 11 bidan, dan 39 kader imunisasi. Pembagian responden berdasarkan tempat kerja, yaitu 34,4\% di rumah sakit, 28\% di Puskesmas, $31,2 \%$ di Posyandu, dan 6,4\% di klinik pribadi. Tabel 1 
menjabarkan pertanyaan kuesioner mengenai pelayanan imunisasi.

Responden juga ditanya mengenai masalah yang dialami yang menghasilkan penurunan cakupan imunisasi di fasilitas kesehatan masing-masing (Gambar $1)$.
Seratus empat puluh lima orangtua mengikuti penelitian ini. Distribusi responden berdasarkan tempat imunisasi, yaitu 28,3\% di rumah sakit, 35,2\% Puskesmas, 27,6\% Posyandu, dan 8,9\% klinik pribadi. Tabel 2 menjabarkan pertanyaan pada orangtua untuk mengevaluasi masalah yang mengakibatkan penundaan imunisasi.

Tabel 1. Pertanyaan mengenai pelayanan imunisasi untuk tenaga kesehatan

\begin{tabular}{|c|c|c|c|}
\hline No. & Pertanyaan & $\mathrm{Ya}(\%)$ & Tidak (\%) \\
\hline 1. & Apakah selama pandemi Covid-19 pasien yang datang untuk imunisasi berkurang? & 96 & 4 \\
\hline 2. & Apakah layanan imunisasi di tempat anda bekerja sempat dihentikan saat PSBB? & 53,6 & 46,4 \\
\hline 3. & $\begin{array}{l}\text { Apakah di tempat anda bekerja terdapat sistem dimana anak yang tertinggal imunisasi } \\
\text { karena PSBB dicatat lalu dijadwalkan di kemudian hari? }\end{array}$ & 70,4 & 29,6 \\
\hline 4. & $\begin{array}{l}\text { Apakah tenaga medis imunisasi di tempat anda bekerja dialihkan untuk pelayanan } \\
\text { Covid-19? }\end{array}$ & 27,2 & 72,8 \\
\hline 5. & $\begin{array}{l}\text { Apakah ruangan imunisasi di tempat anda bekerja dialihkan untuk pelayanan } \\
\text { Covid-19? }\end{array}$ & 4,8 & 95,2 \\
\hline 6. & Apakah di tempat anda bekerja terdapat fasilitas untuk pelayanan imunisasi? & 19,2 & 80,8 \\
\hline 7. & $\begin{array}{l}\text { Apakah petugas imunisasi di tempat anda bekerja mendapat Alat Pelindung Diri } \\
\text { (APD) yang sesuai? }\end{array}$ & 82,4 & 17,6 \\
\hline 8. & $\begin{array}{l}\text { Apakah di tempat anda bekerja terdapat poster/banner/iklan bentuk lainnya untuk } \\
\text { mendorong masyarakat untuk imunisasi kembali? }\end{array}$ & 60,8 & 39,2 \\
\hline 9. & $\begin{array}{l}\text { Adakah anak di tempat anda bekerja yang tertunda imunisasi karena terdiagnosa/ } \\
\text { dicurigai Covid-19? }\end{array}$ & 18,4 & 81,6 \\
\hline 10. & $\begin{array}{l}\text { Apakah di tempat anda bekerja di data berapa banyak jumlah penyakit yang dapat } \\
\text { dicegah dengan imunisasi muncul selama pandemi? }\end{array}$ & 32,0 & 68,0 \\
\hline
\end{tabular}

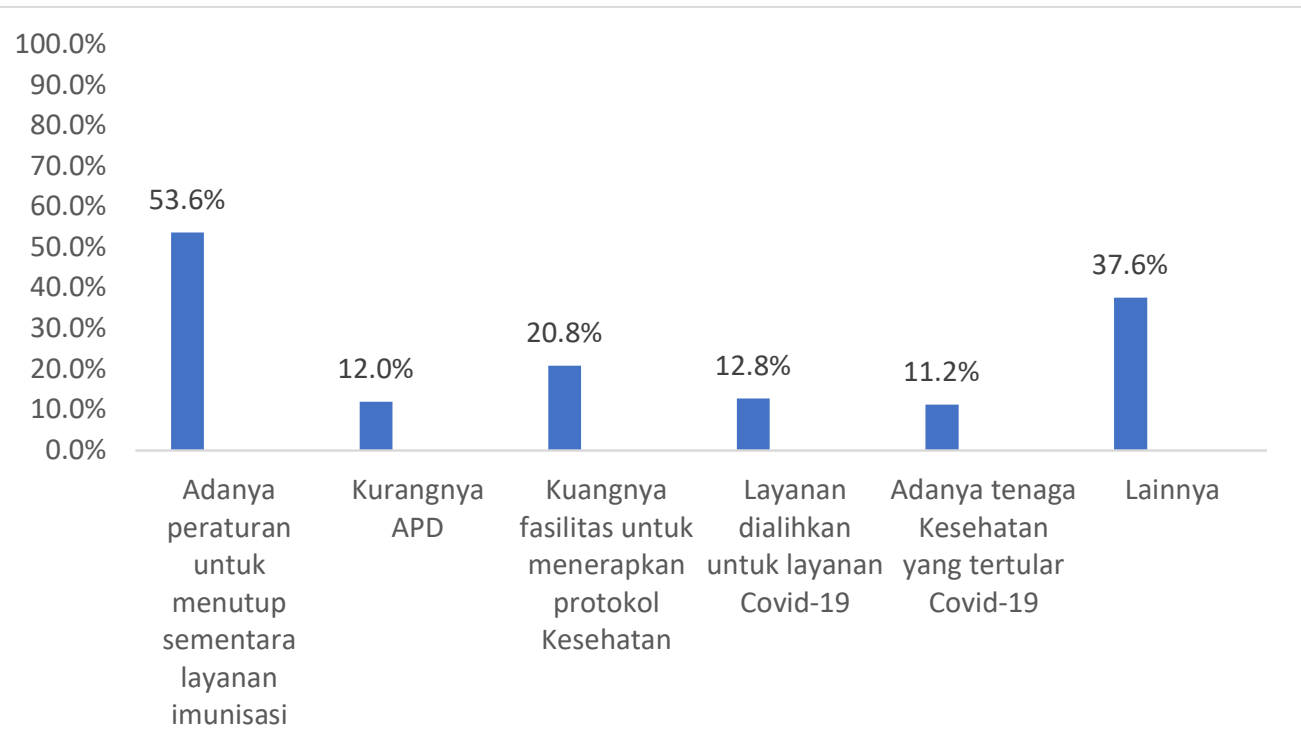

Gambar 1. Masalah yang dialami tenaga kesehatan dalam memenuhi cakupan imunisasi 
Tabel 2. Pertanyaan yang diajukan pada orangtua mengenai penundaan imunisasi

\begin{tabular}{|c|c|c|c|}
\hline No. & Pertanyaan & Ya (\%) & Tidak (\%) \\
\hline 1. & Apakah selama masa PSBB imunisasi anak anda tertunda? & 69,7 & 30,3 \\
\hline 2. & Apakah pelayanan imunisasi di tempat yang anda biasa kunjungi dihentikan karena Covid-19? & 59,3 & 40,7 \\
\hline 3. & $\begin{array}{l}\text { Apakah anda memutuskan untuk membawa anak anda ke tempat lain untuk mendapatkan } \\
\text { imunisasi? }\end{array}$ & 29,0 & 71,0 \\
\hline 4. & $\begin{array}{l}\text { Apakah anda akan merasa nyaman bila membawa anak anda untuk imunisasi ke fasilitas } \\
\text { kesehatan yang memisah pelayanan anak sehat dan anak sakit? }\end{array}$ & 95,9 & 4,1 \\
\hline 5. & $\begin{array}{l}\text { Apakah anda akan merasa nyaman bila membawa anak anda untuk imunisasi ke fasilitas } \\
\text { kesehatan dimana petugas imunisasi memakai APD sesuai? }\end{array}$ & 96,6 & 3,4 \\
\hline 6. & $\begin{array}{l}\text { Apakah ada akan merasa nyaman bila membawa anak anda untuk imunisasi ke fasilitas } \\
\text { kesehatan yang menerapkan protokol pencegahan Covid-19 seperti jaga jarak dan ketersediaan } \\
\text { air dan sabun/ hand sanitizer? }\end{array}$ & 97,2 & 2,8 \\
\hline 7. & $\begin{array}{l}\text { Apakah anda dihubungi oleh tenaga kesehatan setempat untuk mengingatkan anda untuk } \\
\text { membawa anak imunisasi? }\end{array}$ & 38,6 & 61,4 \\
\hline 8. & $\begin{array}{l}\text { Apakah anda melihat banner/poster/iklan media sosial/iklan bentuk lainnya untuk membujuk } \\
\text { anda untuk membawa anak imunisasi? }\end{array}$ & 42,8 & 57,2 \\
\hline 9. & $\begin{array}{l}\text { Apakah imunisasi anak anda tertunda karena tidak terdapat vaksin tertentu di fasilitas } \\
\text { kesehatan yang anda kunjungi? }\end{array}$ & 21,4 & 78,6 \\
\hline
\end{tabular}

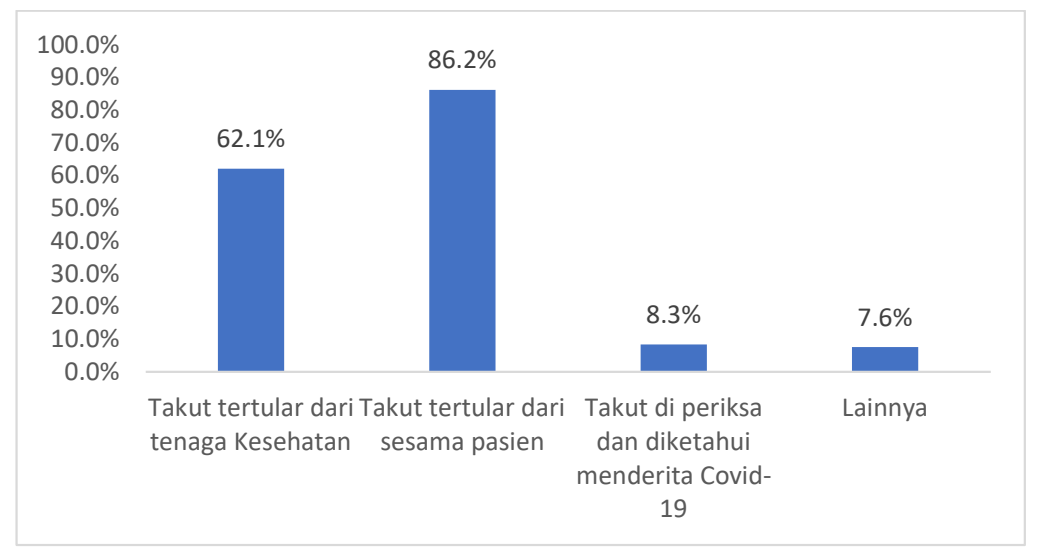

Gambar 2. Hal yang ditakutkan oleh orangtua dalam membawa anak ke fasilitas kesehatan

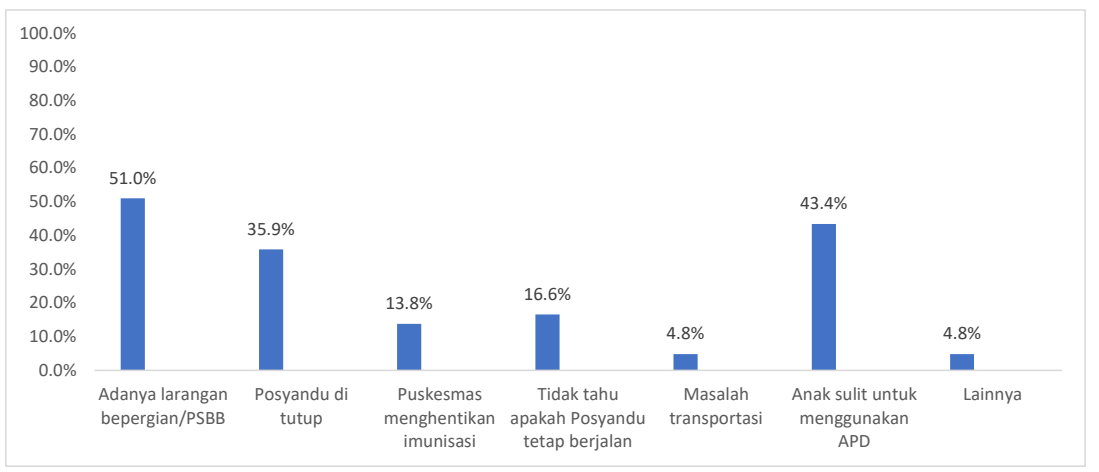

Gambar 3. Masalah yang dialami orangtua dalam melengkapi imunisasi selama masa pandemi Covid-19. 
Orangtua juga ditanyakan mengenai ketakutan serta masalah yang dialami dalam membawa anak untuk imunisasi (Gambar 2 dan 3).

\section{Pembahasan}

Pandemi Covid-19 telah mengganggu, menunda, dan menghentikan pelayanan imunisasi rutin. Berbagai negara mengalami penurunan cakupan imunisasi. Masalah ini akan menimbulkan peningkatan kasus PD3I yang sebelumnya sudah cukup terkendali atau tereliminasi. Penyebab dari penurunan cakupan imunisasi ini adalah ketakutan orangtua, peraturan lockdown, tenaga kesehatan sibuk dengan pelayanan Covid-19 dan masalah logististik, seperti pendistribusian vaksin ke fasilitas kesehatan. ${ }^{17}$

Terganggunya pelayanan imunisasi terutama dirasakan pada negara berpenghasilan menengah dan rendah, seperti Pakistan. Angka cakupan imunisasi sebelum pandemi pada negara ini sudah cukup rendah. Akibat dari penurunan cakupan imunisasi tersebut, berbagai kasus campak dan difteri mulai ditemukan di Pakistan. Selain itu, Program Polio Nasional Pakistan yang seharusnya memberikan imunisasi Polio kepada 40 juta anak di bawah 5 tahun tertunda akibat pandemi Covid-19 karena 25000 tenaga kesehatan yang seharusnya membantu program ini, sekarang dialihkan untuk pelayanan Covid-19. ${ }^{4}$

Suatu survei online dilakukan oleh Kementerian Kesehatan Indonesia dan UNICEF Indonesia yang melibatkan 7558 orangtua dan menanyakan pendapat mereka mengenai pemberian imunisasi pada masa pandemi. Hasil survei memperlihatkan bahwa orangtua mengalami masalah melengkapi imunisasi karena penutupan Posyandu dan Puskesmas serta ketakutan akan tertular Covid-19. ${ }^{12}$ Namun, penelitian tersebut tidak menjelaskan secara detail alasan yang menyebabkan penurunan cakupan imunisasi. Selain itu, juga belum ada penelitian terpublikasi mengenai kesulitan yang dialami tenaga kesehatan di Indonesia dalam memenuhi cakupan imunisasi. Penelitian kali ini bertujuan untuk mencari alasan tersebut.

Pada penelitian ini, 96\% tenaga kesehatan melaporkan penurunan angka imunisasi pada tempat kerja mereka. Sisanya bekerja di rumah sakit, dimana angka imunisasi tetap sama dan juga di klinik yang hanya memberi pelayanan imunisasi. Lebih dari setengah dari jumlah responden melaporkan bahwa pelayanan imunisasi di tempat kerja mereka dihentikan sementara selama PSBB. Fasilitas kesehatan yang masih melanjutkan pelayanan imunisasi pada masa pandemi, yaitu rumah sakit, Puskesmas, dan klinik pribadi. Padahal, sebagian besar penduduk Jakarta maupun Indonesia sangat bergantung kepada Posyandu untuk pemberian imunisasi karena lokasi yang dekat rumah dan pelayanan yang gratis. Namun, saat pandemi semua Posyandu di seluruh Jakarta dihentikan dan belum di mulai hingga Desember 2020.

Sebanyak 27,2\% tenaga kesehatan melaporkan bahwa petugas imunisasi di tempat kerja mereka dialihkan untuk pelayanan Covid-19. Tidak ada perbedaan signifikan antara jumlah petugas yang dialihkan ke pelayanan Covid 19 antara rumah sakit, Puskesmas, dan klinik pribadi. Sebanyak 4,8\% tenaga kesehatan melaporkan bahwa poli imunisasi digunakan untuk pelayanan Covid-19. Hal ini ditemukan hanya pada klinik pribadi dan rumah sakit, sedangkan untuk poli imunisasi di Puskesmas tidak dipakai untuk pelayanan lain.

Sebanyak 70,4\% tenaga kesehatan memiliki sistem bahwa anak yang tertinggal imunisasi akan dicatat dan dihubungi kemudian hari. Sistem pencatatan ini ditemukan paling tinggi adalah di Puskesmas, diikuti Posyandu, klinik pribadi, dan rumah sakit. Hal ini dapat dimengerti karena Puskesmas dan Posyandu merupakan fasilitas kesehatan tingkat primer yang selama ini telah dibina oleh Pemerintah dan telah memiliki sistem pencatatan dan pelaporan imunisasi yang jelas.

Sebanyak $82,4 \%$ responden tenaga kesehatan mengakui bahwa mereka memiliki alat pelindung diri/ APD yang sesuai untuk melakukan pelayanan imunisasi. Angka tertinggi ditemukan di Puskesmas, diikuti klinik pribadi, dan rumah sakit. Masalah ketersediaan APD juga menjadi masalah global, dan ditemukan baik di negara berkembang maupun di negara maju disebabkan peningkatan kasus Covid-19 yang sangat cepat terutama pada awal pandemi. Negara seperti Pakistan, Eropa, Amerika Latin dan Amerika Serikat melaporkan kekurangan APD pada awal pandemi. ${ }^{18-21}$

Sebanyak 60,8\% tenaga kesehatan melaporkan bahwa di tempat kerja mereka terdapat iklan imunisasi, yaitu paling banyak responden yang bekerja di Puskesmas dan rumah sakit. Selain itu, hanya 19,2\% fasilitas kesehatan memiliki fasilitas home-visit untuk pemberian imunisasi yang terdiri dari rumah sakit dan klinik pribadi. 
Pada penelitian ini, hanya $18,4 \%$ tenaga kesehatan yang melaporkan bahwa imunisasi tertunda karena terdapat anak yang terdiagnosis atau dicurigai Covid-19. Beberapa penyebab lain yang menurunkan cakupan imunisasi adalah adanya peraturan Pemerintah untuk menghentikan sementara layanan imunisasi, kurangnya APD, kurangnya fasilitas untuk menerapkan protokol kesehatan, layanan dialihkan untuk layanan Covid-19 dan adanya tenaga kesehatan yang tertular Covid-19. Peraturan lockdown yang diterapkan pada berbagai negara menyebabkan penurunan cakupan imunisasi secara drastis. Badan dan mitra kesehatan dunia, seperti WHO, UNICEF, dan GAVI melaporkan bahwa setidaknya 68 negara mengalami penurunan cakupan imunisasi yang diakibatkan oleh restriksi sosial. ${ }^{22} \mathrm{Di}$ India diestimasikan bahwa sekitar 5 juta anak tidak di imunisasi karena peraturan pemerintah. ${ }^{23}$ Di Pakistan terdapat sekitar 2735 anak per hari yang tidak mendapat imunisasi pada masa lockdown. ${ }^{24}$

Penelitian ini memperlihatkan bahwa tenaga kesehatan mengalami masalah dalam membujuk orangtua untuk melengkapi imunisasi yaitu ketakutan orangtua untuk mengunjungi fasilitas, kesulitan dalam menghubungi orangtua, dan rumor anti vaksin. Masalah lain bagi tenaga kesehatan, yaitu hoax mengenai Covid-19, fasilitas kesehatan jauh dari rumah, takut berkunjung ke tempat ramai, dan masalah finansial untuk mendapat imunisasi di fasilitas kesehatan swasta karena biaya pelayanan ditanggung pribadi.

Antivaksin merupakan masalah yang sudah ada lama sebelum pandemi. Keraguan untuk memberikan imunisasi dikarenakan berbagai alasan, seperti alasan berlandaskan dasar agama, sosioekonomi dan juga ketakutan akan efek samping imunisasi tersebut. Dengan timbulnya pandemi Covid-19, keraguan ini makin bertambah. ${ }^{25}$

Sebagian besar dari orangtua $(69,7 \%)$ menunda imunisasi selama pandemi. Sebanyak 59,3\% melaporkan bahwa pelayanan imunisasi dihentikan di tempat yang biasa dikunjungi dan hanya 29\% responden membawa anak untuk imunisasi di tempat lain. Beberapa orangtua mengakui bahwa terdapat tenaga kesehatan yang menghubungi mereka untuk melengkapi imunisasi $(38,6 \%)$ yang ditemukan paling tinggi di Posyandu diikuti rumah sakit, Puskesmas, dan klinik pribadi. Hal ini memperlihatkan usaha tenaga kesehatan dalam mencoba meningkatkan kembali angka cakupan imunisasi.
Keraguan orangtua berperan besar dalam penurunan cakupan imunisasi. Orangtua takut akan terinfeksi Covid-19 dari tenaga kesehatan maupun pasien lain dan juga takut akan dilakukan pemeriksaan Covid-19 dan dinyatakan positif. Selain itu, juga terdapat masalah lain, yaitu peraturan PSBB, pelayanan imunisasi Posyandu maupun Puskesmas dihentikan, kurangnya informasi mengenai pelayanan imunisasi di Puskesmas, masalah transportasi, dan kesulitan dalam memakaikan APD pada anak seperti masker atau face-shield.

Sebagian besar orangtua mengakui bahwa mereka akan bersedia membawa anak untuk imunisasi ke fasilitas kesehatan yang mengikuti protokol kesehatan. Orangtua berpendapat bahwa fasilitas kesehatan yang ideal menurut mereka adalah yang menyediakan APD untuk pasien, menerapkan aturan physical distancing dan memiliki fasilitas air mengalir dan sabun atau hand sanitizer untuk menjaga kebersihan tangan. Selain itu, orangtua juga mengharapkan fasilitas kesehatan memisahkan pelayanan anak sakit dengan anak sehat, memiliki sistem perjanjian untuk mencegah keramaian, melakukan desinfeksi ruangan rutin, dan menyediakan sistem fast-track untuk pelayanan imunisasi agar tidak harus tunggu terlalu lama.

Keterbatasan penelitian ini yaitu distribusi responden tenaga kesehatan yang tidak rata antara fasilitas kesehatan primer, rumah sakit dan klinik pribadi serta sebagian besar responden orangtua memiliki tingkat sosioekonomi rendah.

\section{Kesimpulan}

Cakupan imunisasi mengalami penurunan di Indonesia, maupun negara lain. Masalah ini dapat menimbulkan peningkatan kasus PD3I pada saat atau setelah pandemi Covid-19. Penurunan cakupan imunisasi ini disebabkan oleh berbagai faktor termasuk keraguan dan ketakutan orangtua serta permasalahan dalam pelayanan imunisasi di berbagai fasilitas kesehatan. Meskipun penelitian ini memiliki keterbatasan, yaitu distribusi responden tenaga kesehatan yang tidak merata antarfasilitas kesehatan dan sebagian besar orangtua memiliki tingkat sosioekonomi rendah. Penelitian ini diharapkan dapat menjadi dasar dalam mencari jalan keluar untuk meningkatkan cakupan imunisasi dan mengurangi kejadian PD3I. 


\section{Daftar pustaka}

1. Ranganathan R, Khan AM. Routine immunization services during the coronavirus (COVID-19) pandemic. Indian J Community Health 2020;32:236-9.

2. World Health Organization. Immunization. Geneva: WHO; 2019 Diakses pada 26 Maret 2021Didapat dari: https://www. who.int/topics/immunization/en/; 2020.

3. Kirmani S, Saleem A. Impact of Covid-19 pandemic on paedetric services at a referral center in Pakistan: lessons from a low-income and middle-income country setting. Arch Dis Child Epub ahead of print; 2020;0:1-2.

4. Roberton T, Carter ED, Chou VB, dkk. Early estimates of the indirect effects of the COVID-19 pandemic on maternal and child mortality in low-income and middle-income countries: a modelling study. Lancet Glob Health 2020;8:901-8.

5. Adamu AA, Jalo RI, Habonimana D, Wiysonge CS. COVID-19 and routine childhood immunization in Africa: Leveraging systems thinking and implementation science to improve immunization system performance. Int J Infect Dis 2020;98:161-5.

6. World Health Organization. At least 80 million children under one at risk of diseases such as diphtheria, measles and polio as COVID-19 disrupts routine vaccination efforts, warn Gavi, WHO and UNICEF; 2020.

7. Kementerian Kesehatan Republik Indonesia. Health management information system; 2020. Jakarta: Kemkes; 2020.

8. UNICEF, Kementerian Kesehatan Republik Indonesia. Penilaian Cepat: Dampak Pandemi COVID-19 terhadap Layanan Imunisasi di Indonesia. Jakarta: Kemkes;2020.

9. Sub-divisi imunisasi, Kementerian Kesehatan republik Indonesia. Cakupan imunisasi tahun 2019. Jakarta: Kemkes; 2019.

10. Sub-divisi imunisasi, Kementerian Kesehatan republik Indonesia. Cakupan imunisasi tahun 2020. Jakarta: Kemkes; 2020.

11. Kementerian Kesehatan republik Indonesia. Satuan tugas penanganan Covid-19. Diakses pada 19 Desember 2020. Didapat dari: https://covid19.go.id/.

12. Kementerian Kesehatan republik Indonesia WHO Indonesia. Routine immunization for children during the COVID-19 Pandemic in Indonesia: perceptions of parents and caregivers. Jakarta: Kemkes RI WHO Indonesia; 2020.

13. Helen M, Elise T, Joanne W, dkk. Early impact of the coronavirus disease (COVID-19) pandemic and physical distancing measures on routine childhood vaccinations in England, January to April 2020. Euro Surveill 2020;25:1-6.

14. Bramer CA, Kimmins LM, Swanson R, dkk. Decline in child vaccination coverage during the COVID-19 Pandemic - Michigan Care Improvement Registry, May 2016-May 2020. Morbidity and Mortality Weekly Report 2020;69:630-1.

15. World Health Organization. Guiding principles for immunization activities during the COVID-19 pandemicInterim Guidance. Geneva: WHO; 2020.

16. World Health Organization. Frequently asked questions (FAQ) immunization in the context of COVID-19 pandemic. Geneva: WHO; 2020.

17. Dinleyici EC, Borrow R, Safadi MAP, Damme PV, Munoz FM. Vaccines and routine immunization strategies during the COVID-19 pandemic. Hum Vaccin Immunother 2020;17:400-7.

18. Ahmed J, Malik F, Arif TB dkk. Availability of personal protective equipment (PPE) among US and Pakistani Doctors in COVID-19 pandemic. Cureus J Med Sci 2020;12:8550.

19. Delgado JM, Viteri E, Mula A dkk. Availability of personal protective equipment and diagnostic and treatment facilities for healthcare workers involved in COVID-19 care: A cross-sectional study in Brazil, Colombia, and. PLOS one 2020;15:1-13.

20. Mantelakis A, Spiers HVM, Lee CW, Chambers A, Joshi A. Availability of personal protective equipment in NHS Hospitals during COVID-19: a national survey. Ann Work Expo Health 2020; 65:136-40.

21. Cohen J, Rodgers Y. Contributing factors to personal protective equipment shortages during the COVID-19 pandemic. JPrevent Med 2020;141:1-7.

22. Lassi ZS, Naseem R, Salam RA, Siddiqui F, Das J. The impact of the COVID-19 pandemic on immunization campaigns and programs: a systematic review. Int J Environ Res Pub Health 2021;18:988.

23. Ghatak N, Marzo RR, Saleem SM, Sharma N, Bhattacharya $S$, Singh A. Impact on routine immunization services during the lockdown period in India: implications and future recommendations. Ann Trop Med Pub Health 2020;23:1-6.

24. Chandir S, Siddiqi DA, Setayesh H, Khan AJ. Impact of COVID-19 lockdown on routine immunisation in Karachi, Pakistan. The Lancet Global Health 2020;8:118-20.

25. Sallam M. COVID-19 vaccine hesitancyworldwide: A concise systematic review of vaccine acceptance rates. Vaccines 2021;9:1-14. 